\title{
Recent insights into the biology of Barrett's esophagus
}

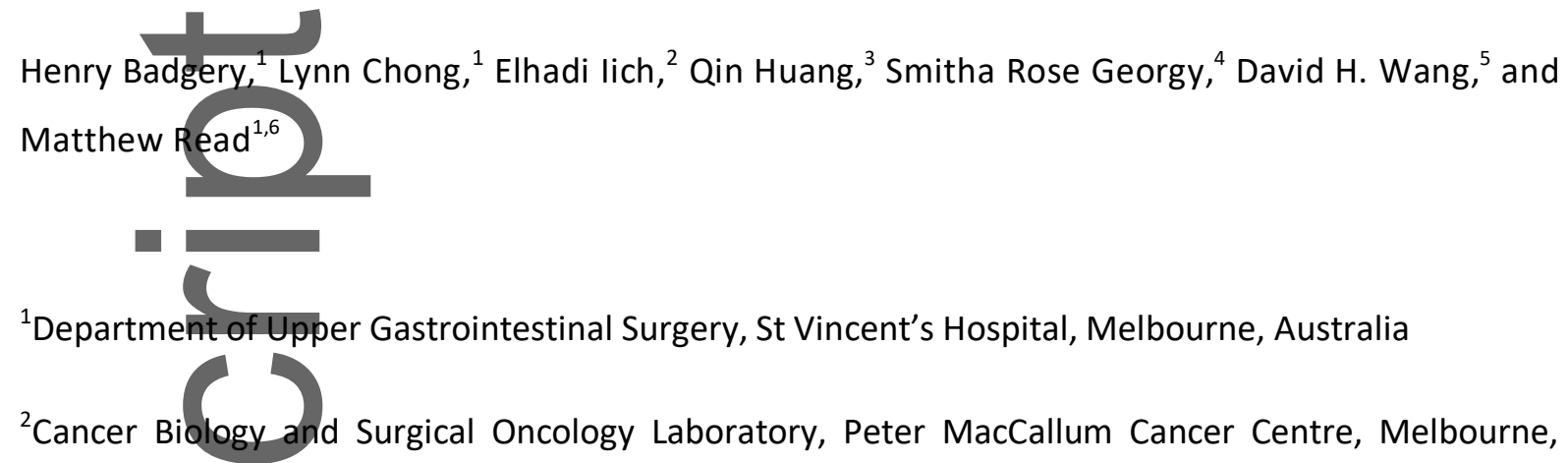

Australia

${ }^{3}$ Department of Pathology and Laboratory Medicine, Veterans Affairs Boston Healthcare System and Harvard Medical School, West Roxbury, Massachusetts

${ }^{4}$ Department of Anatomic Pathology, Faculty of Veterinary and Agricultural Sciences, The University of Melbourne, Melbourne, Australia

${ }^{5}$ Department of Hematology and Oncology, UT Southwestern Medical Centre and VA North Texas Health Care System, Dallas, Texas

${ }^{6}$ Department of Surgery, The University of Melbourne, St Vincent's Hospital, Melbourne, Australia

Address for correspondence:
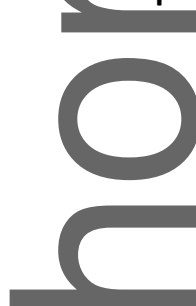

Short title: Barrett's biology

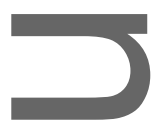

Dr Henry Badgery

Department of Surgery

St Vincent's Hospital

41 Victoria Parade, Fitzroy, Vic, Australia, 3065

badgeryhe@gmail.com

This is th cuth $\mathrm{r}$ manuscript accepted for publication and has undergone full peer review but has not been througn copyediting, typesetting, pagination and proofreading process, which may lead to differences between this version and the Version of Record. Please cite this article as doi:

$\underline{10.1111 / \text { nyas. } 14432 .}$.

This article is protected by copyright. All rights reserved. 
Keywords: Barrett's esophagus; signaling pathways; esophageal adenocarcinoma; epithelial barrier function; molecular reprogramming

\section{Abstract}

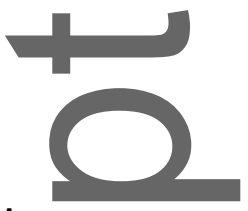

Barrett's esophagus (BE) is the only known precursor to esophageal adenocarcinoma (EAC), an aggressive cancer with a poor prognosis. Our understanding of the pathogenesis and of Barrett's metaplasia is incomplete, and this has limited the development of new therapeutic targets and agents, risk stratification ability, and management strategies. This review outlines current insights into the biology of $\mathrm{BE}$ and addresses controversies surrounding cell of origin, cellular reprogramming theories, updates on esophageal epithelial barrier function, and the significance of goblet cell metaplasia (GCM) and its association with malignant change. Further research into the basic biology of $\mathrm{BE}$ is vital as it will underpin novel therapies and improve our ability to predict malignant progression and help identify the minority of patients who will develop EAC.

Introduction
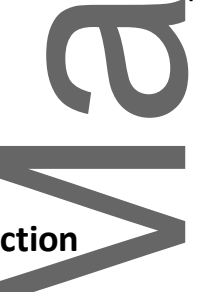

Barrett's esophagus (BE) is a metaplastic lesion that arises in the lower esophagus in response to gastro-esophageal reflux disease (GERD). In this metaplastic process, the normal stratified squamous epithelium of the lower esophagus is replaced by columnar epithelium with features of both gastric and intestinal phenotypes. ${ }^{1}$ The study of BE is clinically significant as it is the only known precursor lesion for esophageal adenocarcinoma (EAC). While recent clinical trials have been able to demonstrate improvements in overall survival and pathological response, the prognosis of EAC remains poor. ${ }^{2-4}$ Furthermore, the incidence of EAC in Western countries continues to rise. ${ }^{5}$ Progression from $B E$ to $E A C$ is a rare event, associated with multiple factors including length, histology indicating the presence of goblet cells, obesity, dysplasia, and age. ${ }^{6-9}$

This article is protected by copyright. All rights reserved. 
Current theories suggest that the development of $\mathrm{BE}$ is due to a complex interplay between environmental exposures, molecular genetics, and cellular interactions. Unfortunately, the exact mechanisms responsible for the development of $\mathrm{BE}$ are poorly understood. As a result, molecular therapies capable of either preventing or treating the disease have been lacking. The aim of this review is to provide an update on a number of key areas relating to the biology of BE. These include controversial areas such as the defining features of BE as well as the Barrett's cell of origin. In addition, we also review recent advances in molecular biology as well as the emerging concept of the importance of the epithelium in maintaining barrier function.

\section{Definition of Barrett's esophagus and the significance of goblet cell metaplasia

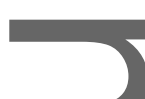

The pathological diagnosis of $\mathrm{BE}$ has been challenged in recent years as to the requirement for intestinal metaplasia, which is characterized by the presence of goblet cells. As a result, the definition of $\mathrm{BE}$ tends to vary among different societies. ${ }^{10-15}$ Histologically, BE is defined by three types of metaplastic columnar cells: goblet cells (i.e., specialized intestinal metaplasia), cardiac (mucinous), and cardiofundic (mucoxyntic) cells. As goblet cell metaplasia (GCM) is associated with malignant progression of $B E$ to EAC, histologic identification of the presence of GCM for pathologic diagnosis of BE is required by The American Gastroenterology Association and is the focus of this review.

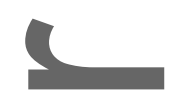

It is well known that EAC develops over time by accumulating genetic and epigenetic abnormalities in metaplastic goblet cells. As such, GCM present at the initial index biopsy becomes crucially important as a histologic biomarker for prediction of malignant progression. The results of several histopathologic and molecular studies support this concept. In 2007, Younes et al. compared prognosis in 78 patients with $(n=43)$ or without $(n=35)$ GCM at initial index biopsies. ${ }^{17}$ They reported that after an average of 72 months (range 12-146) of the follow-up period, malignant progression was identified only in patients with GCM. These findings were confirmed in another similar study with a much larger sample of 708 patients without a prior diagnosis of BE. ${ }^{18}$ In that study, GCM was identified in 39\% (276/708) compared with 54\% (379/708) without GCM. In this series, GCM was associated with a significantly longer length (mean: $4.6 \mathrm{~cm}$ ) of columnar-lined esophagus compared to those without GCM (mean: $1.6 \mathrm{~cm}$ ). Importantly, malignant progression was

This article is protected by copyright. All rights reserved. 
again identified only in cases with GCM. More recently, Pohl et al. (2015) demonstrated an association of the length of BE with the development of EAC irrespective of the presence of GCM. ${ }^{6}$ The findings of Younes et al. are supported by the discovery of significantly more extensive genetic abnormalities in GCM, compared with those without GCM. Bandla et al. conducted several genetic tests on all exons of EAC mutation-related genes and fluorescence in situ hybridization (FISH) analysis for DNA copy number abnormalities. ${ }^{19}$ They reported that loss of CDKN2A, amplification of chromosome 8, and DNA copy number abnormalities were detected only in GCM. Further targeted gene sequencing showed 11 non-synonymous mutations in 16 samples with GCM but only 2 such mutations in 19 controls without GCM. DNA copy number abnormalities (FHIT, MYC, CDKN2A/p16, WWOX, and GATA6) were absent in cases without GCM but present in various proportions of cases with GCM in a pattern similar to early stage (pT1) EAC lesions. They concluded that columnar-lined esophagus with GCM was associated with a high frequency of cancer-related genetic mutations than without. ${ }^{19}$ As such, the status of GCM has been used not only for BE diagnosis ${ }^{1}$ but also for BE patient surveillance in clinical practice. ${ }^{11}$

\section{GERD and the role of the epithelium in maintaining barrier function}

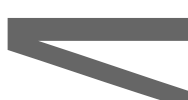

One of the earliest changes in the pathogenesis of BE is the loss of mucosal integrity. Therefore, in order to better understand the pathophysiological drivers of $\mathrm{BE}$, an understanding of how the epithelial barrier is formed and maintained as well as the structural and functional modifiers of this epithelial barrier are essential.

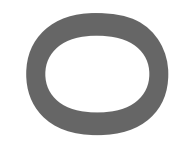

The esophagus is challenged by a myriad of mechanical, biological, and chemical insults every day. As a result, a number of well-established mechanisms exist in order to protect the esophageal mucosa. These include pre-epithelial, epithelial, and post-epithelial compartments.

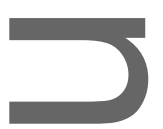

The pre-epithelial defense mechanisms include water and bicarbonate ions derived from swallowed saliva, secretions from esophageal submucosal glands, and the coordinated movement of the esophagus and lower esophageal sphincter to prevent reflux. ${ }^{20}$ Esophageal protective factors also include mucin, non-mucin proteins, epidermal growth factor (EGF), prostaglandin E2 (PGE2), and 
transforming growth factor- $\alpha$ (TGF $\alpha$ ), which are all secreted when the mucosal integrity is challenged. ${ }^{21,22}$

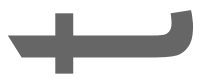

The epithelial component is comprised of stratified squamous epithelium that forms a barrier to the outside environment. Key components within this compartment include the tight junction complex, adherens junctions, and desmosomes, which all function to restrict the paracellular movement of molecules. Differential expression of junctional complex proteins have been reported in the pathologic processes of the esophagus as well as during alterations in the environment. ${ }^{23}$ Other key components within this compartment include filaggrin, one of the late epidermal differentiation proteins, which plays a pivotal role in the front line defense of the barrier function and the intercellular glycoprotein matrix. ${ }^{24,25}$

Post-epithelial defense comprises mucosal blood flow, restitution and replication of esophagea epithelial cells, and maintenance of tissue acid-base status. The defense against exposure to hydrogen ions during gastroesophageal reflux involves a hyperemic reaction of esophageal mucosa to deliver bicarbonates for buffering and to remove hydrogen ions, lactic acid, and $\mathrm{CO}_{2}$. Prolonged exposure to gastric acids inevitably results in cell injury and necrosis. Defense against this involves epithelial restitution, a rapid form of repair over 30 to 60 minutes, whereby adjacent healthy cells migrate to the damaged area. In contrast, epithelial replication is a slow process ranging from days to weeks, depending on the size of the injury. ${ }^{26}$

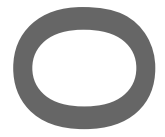

In addition, a number of anti-reflux mechanisms also exist in order to protect the esophagus. These include the lower esophageal sphincter with its associated high-pressure zone, as well as extrinsic factors such as the diaphragmatic sphincter, the presence of an intra-abdominal portion of esophagus, the "angle of His", and the phrenoesophageal ligament. ${ }^{27}$ Disruption to any of these mechanisms has the potential to lead to gastroduodenoesophageal reflux, the key noxious contents of which include acid, pepsin, and bile. By disturbing the local pH-ion balance, acid has a direct injurious effect on the epithelium. It also acts indirectly by activating pepsin, a proteolytic enzyme, leading to an impaired mucosal barrier. In contrast, bile is able to pass directly into cells and disrupt cellular function by virtue of its lipophilic properties. ${ }^{28}$ Exposure to acid and bile also induces pro- 
inflammatory cytokines such as interleukin- 8 and $-1 \beta$ which have a direct effect on junctional complex proteins, thereby altering paracellular transit of molecules. ${ }^{29}$ This is supported by experimental studies in mice where overexpression of IL-1 $\beta$ in the stratified squamous epithelium at the squamocolumnar junction (SCJ) led to a Barrett's-like metaplasia. ${ }^{30}$

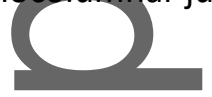

-

One of the earliest changes in the pathogenesis of BE is the loss of mucosal integrity, and detecting the initiating events of epithelial barrier dysfunction may help to stratify patients with GERD and predict the progression of the disease. To better understand the pathophysiological drivers of $\mathrm{BE}$, an understanding of how the epithelial barrier is formed and maintained in the esophagus as well as the structural and functional modifiers of this epithelial barrier are essential.

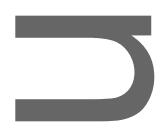

Developing research suggests that barrier changes in esophageal mucosa may be driven by a more generalized inflammatory process induced by the pro-inflammatory cytokines IL- 8 and IL-1 $\beta^{23,29}$ Researchers have shown that overexpression of IL-1 $\beta$ in the stratified squamous epithelium at the $\mathrm{SCJ}$ in mice led to a Barrett's-like metaplasia, indicating the significance of chronic inflammation in $\mathrm{BE} .{ }^{30}$ Low tevels of systemic inflammation associated with abdominal obesity contribute to increased levels of cytokines and their receptors such as tumor necrosis factor- $\alpha, \mathrm{C}$-reactive protein, and leptin.

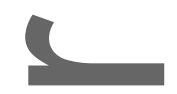

There is also evidence that the transcription factor gene encoding Grainy head-like 3 (GRHL3), which is involved in both the proliferation and differentiation of squamous epithelial cells, plays a critical role in maintaining barrier function. ${ }^{32,33}$ Analysis of the spatial expression pattern of GRHL3 across human organs using RNA-seq combined with antibody-based profiling identified biased expression of GRHL3 in the esophagus (31.7 RPKM), indicating its importance in esophageal biology and disease. ${ }^{34}$ In addition, the gene expression profile from 75 EAC samples compared with 28 paired non-tumor esophageat samples showed marked downregulation of GRHL3 mRNA (15-fold). Reduced GRHL3 expression was also observed with BE samples $(n=15){ }^{35}$

This article is protected by copyright. All rights reserved. 
Other mechanisms responsible for defective epithelial barrier function in BE include mutations involving Myo9B, a Rho family GTPase activating protein involved in epithelial cell cytoskeleton organization, as well as reduced salivary levels of EGF, TGF $\alpha$, and PGE2. These components form part of the pre-epithelial defense and reduced levels predispose the mucosa to severe damage. ${ }^{36}$ This is thought to occur by impairing the restitution and replication of esophageal epithelial cells and by limiting the rate of permeability of hydrogen ions. ${ }^{37}$

Further devetopments markers of barrien function deficiency are important as it may allow us to predict which patients with GERD will developBE and progress to dysplasia and malignancy.

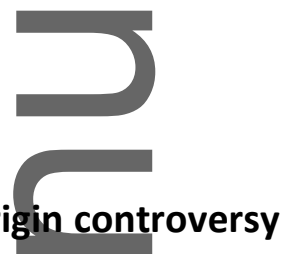

\section{Cell of origin controversy}

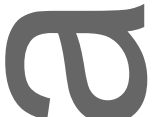

$\mathrm{BE}$ is a stable metaplastic condition that generally does not progress rapidly, if at all, towards EAC. This reflects the need for a progenitor cell that has undergone metaplastic changes (i.e., reprogramming) and is able to maintain the metaplastic tissue over a long period of time. However, the origin of this progenitor cell is still debated, with different models suggesting different sources. The opinions on the cell of origin of BE is subdivided into two groups: intrinsic or extrinsic to the esophagus.

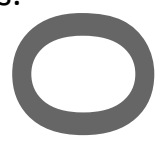

\section{Extrinsic to the esophagus}

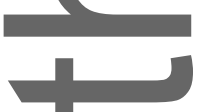

Due to its continuity with the gastric mucosa, early theories proposed that BE could potentially develop through migration of gastric cells into the esophagus to replace the squamous epithelium damaged due to reflux. Support for this migration process came from work by Bremner et al. using dogs that had their normal esophageal mucosa surgically stripped. ${ }^{38}$ Complete or partial normal squamous re-epithelialization was observed in dogs with a functioning LES. Conversely, dogs suffering from reflux showed total or nearly total columnar re-epithelialisation with a gastric 
phenotype. This led the authors to conclude that migration of gastric cells is the source of BE in dogs. ${ }^{38}$ Furthermore, in keeping with this theory, Barrett's metaplasia contains cells with a gastric phenotype and is known to express markers also found in the stomach, such as MUC5AC and TFF2. ${ }^{39}$

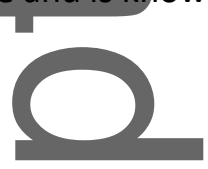

Supporting this hypothesis is the work performed by Quante et al., who used Lgr5-Cre-ERT/RosaLacZ reporter mice to demonstrate the migration of LacZ-labeled Lgr5 $^{+}$gastric progenitor cells. This effect was mediated by inducing chronic inflammation in the esophagus and mouse forestomach. ${ }^{39}$ In this model,an Epstein-Barr virus-driven promoter was used to overexpress IL1 $\beta$ to phenocopy the chronic inflammation seen in humans. IL1 $\beta$ has previously been shown to be increased in BE along with other inflammatory cytokines such as IL6 and IL8. ${ }^{40}$ These mice were shown to develop esophagitis at six months, which further progressed to columnar metaplasia at the SCJ reminiscent of $\mathrm{BE}$ in human. ${ }^{39}$ As a result of the chronic inflammation, migration of LacZ-labeled, stomachderived cells into the inflamed squamous epithelial region at the SCJ was observed. At 20-22 months, these mice developed high grade dysplasia and intramucosal adenocarcinoma at the distal end of the mouse esophagus. Furthermore, these metaplastic changes were shown to occur earlier when the mice were also treated with bile acids or a carcinogen.

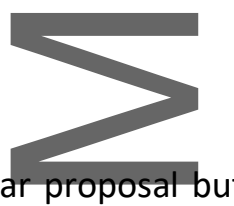

A similar proposal but different cell of origin was proposed by Wang et al. using a p63-null mouse model. ${ }^{41}$ p63 is important for the replacement of the columnar epithelium in the esophagus with squamous epithelium during embryonic development. ${ }^{42}$ Columnar epithelium in p63-null mice was demonstrated to be positive for multiple known BE markers. In their retrospective tracing of the metaplasia in the p63-null mice compared with wildtype (WT) mice, carbonic anhydrase 4 (CAR4) expression was followed in the embryonic columnar esophageal monolayer epithelium of both genotypes. At embryonic day 14, they showed an anterior-to-posterior gradient replacement of $\mathrm{CAR4}^{+} / \mathrm{KRT}^{+}$cells in the WT mice by p63-positive cells, but not in p63-null mice. Furthermore, a small number of CAR4 ${ }^{+}$cells remained at the SCJ of WT adult mice and humans, which were defined as residuat embryonic cells. Finally, through expression of diphtheria toxin driven by the Krt14 promoter to specifically ablate squamous basal layer esophageal cells in adult mice, residual embryonic cells were shown to be capable of expanding proximally to replace the damaged squamous epithelium. ${ }^{41}$ Interestingly, using their ablation model, Wang et al. also found CAR4 $/ \mathrm{KRT7}^{+}$cells expanding proximally into the ablated squamous epithelium. ${ }^{41}$ This suggests the This article is protected by copyright. All rights reserved. 
presence of another cell type at the SCJ that does not fit the residual embryonic cell narrative and is capable of giving rise to columnar epithelium.

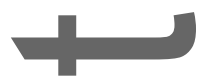

Jiang et du. made a similar observation in their work. ${ }^{43}$ They identified cells sharing both basal/squamous markers (KRT5 and p63) and the columnar marker cytokeratin 7 (KRT7) at the SCJ. Through lineage tracing and overexpression of the basal marker Sox2, expansion of both squamous and a transitional columnar epithelium using $\mathrm{Krt5}-\mathrm{Cre}-E R T / R o s a-S o \times 2-G F P$ transgenic mice was demonstrated, but not in the adjacent gastric epithelium. Purification and culture of basal layer cells

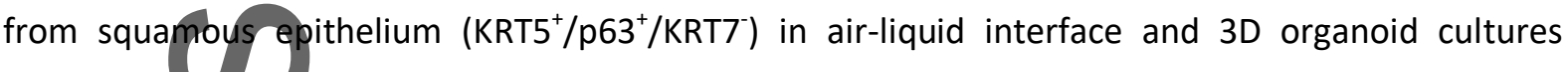
showed that these cells only gave rise to squamous epithelial cultures. Conversely, cells from the transitional epithelium (KRT5 ${ }^{+} / \mathrm{p} 63^{+} / \mathrm{KRT7}^{+}$) generated nonkeratinized epithelium. Jiang et al. further showed ectopic expression of CDX2 in the transitional epithelium to induce Barrett's-like metaplasia through induction of intestinal markers expression such as Mucin 2 (MUC2) and Trefoil factor 3 (TFF3).

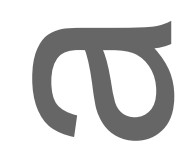

An alternative theory for the development of $\mathrm{BE}$ outside the esophagus was observed in rat esophagojejunostomy models where irradiated female rats received bone marrow cells from male rats. ${ }^{44}$ After eight weeks of reflux exposure, rat esophagi showed ulcerative esophagitis and intestinal metaplasia. Interestingly, using FISH, the authors showed cells within the normal squamous and columnar esophagus possessed a $Y$ chromosome in the female rats. This led the authors to conclude that circulating multipotent progenitor cells from the bone marrow could contribute to the development of $\mathrm{BE} .{ }^{44}$ This, however, most likely reflects solitary inflammatory cells in the inflamed tissue from donor bone marrow cells as there was no clonal expansion of the donor cells in the metaplastic tissue, which would have been expected if these were progenitor cells for the columnar epithelium.

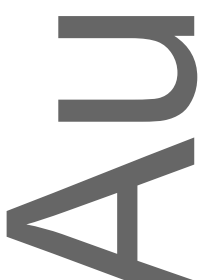

Intrinsic to the esophagus

This article is protected by copyright. All rights reserved. 
Within the esophagus, a likely source of Barrett's metaplasia could arise from squamous epithelial cells, which could directly convert into columnar cells through transdifferentiation. ${ }^{45}$ Evidence supporting this mechanism is supported by scanning electron microscopy showing cells at the junction of Barrett's and normal squamous epithelium with both features of squamous and columnar cells. ${ }^{46}$ This however does not concur with data showing clonality within Barrett's lesion, which indicates a common progenitor, as transdifferentiation is a process which occurs with no or very little proliferation. ${ }^{47,48}$

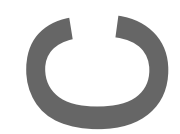

Alternatively, molecular reprogramming of a progenitor cell in the esophagus could give rise to $\mathrm{BE}$. An example of such a phenomenon would be the multi-layered epithelium (MLE) found in BE. ${ }^{49} \mathrm{MLE}$ is a type of proliferating epithelium found generally near or at the neo-squamous junction. ${ }^{50}$ This epithelium shows expression of both squamous and columnar epithelial markers and is considered a transitional stage in the development of $\mathrm{BE} .{ }^{49,50} \mathrm{In} \mathrm{MLE}$, the columnar cells are found overlying the squamous cells, suggesting a conversion of basal layer squamous cells due to exposure to reflux components leading to their phenotype change. ${ }^{50}$ Studies using rat models of reflux via esophagogastroduodenal anastomosis (EGDA) to induce bile exposure in the esophagus ${ }^{51}$ have shown MLE with columnar cells overlying squamous cells, similar to what is found in humans. ${ }^{51}$ However, upon immunohistologic characterization, rat MLE was shown to still harbor expression of the basal/squamous markers p63 and KRT14, which is not seen in human MLE. The authors suggested that in their rat model the basal layer MLE cells maintains a high degree of squamous phenotypecompared with humans.

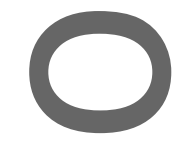

Studies done in the late 1980 s by Gillen et al. (building on the work performed by Bremner et al. ${ }^{38}$ ), used dags as an in vivo model system to study the contribution of gastric cardia to the development of Barrett's $s^{52}$ Gilleh et al. performed a cardioplasty with mucosal stripping and induction of acid reflux alone or in combination with bile. To determine whether gastric cardia is the source of Barrett's, this group excised circumferentially the mucosa directly above the SCJ, leaving a 2-cmwide ring of intact squamous epithelium as a barrier to prevent any potential SCJ or gastric cell migration, while removing another 2-cm-wide ring above the intact mucosa. After induction of reflux, all dogs showed columnar epithelium in the lower region of excised epithelium. However, two of the five dogs also showed columnar epithelium above the intact squamous ring in the acid-alone 
group. Importantly, they saw from their histology what was described as a submucosal gland duct in continuity with the Barrett's epithelium. ${ }^{52}$ These observations led the authors to conclude that the metaplastic epithellium arises from a cell originating from the submucosal gland or duct.

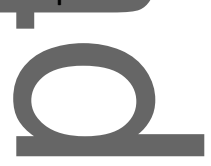

In humans, Coad et al. studied serial sections of BE tissue resections where they observed continuity between submucosal gland ducts and the overlying Barrett's epithelium and the distinct regions of normal squamous epithelium within the BE lesions known as squamous islands. ${ }^{53}$ These findings were further supported by Lorinc et al., who studied the distribution of submucosal glands in relation to the type of mucosal epithelium overlying them. ${ }^{54}$ In their work, they found an accumulation of strbmucosal glands underneath the squamous islands in the BE lesions, and a direct connection between the submucosal ducts to the squamous islands. ${ }^{54}$

Using microdissection and genetic analyses to look at mutations within BE lesions, Leedham et al. showed a 16 point mutation in submucosal duct cells and neighboring metaplastic BE at the crypt level, thereby demonstrating clonality between submucosal ducts and BE. ${ }^{55}$ Further evidence for a potential role of submucosal glands in the development of Barrett's has been demonstrated by Chang et al . $^{56}$ Using short-term ex vivo culture of normal esophageal biopsy specimens. They demonstrated the role of retinoic acid (RA) in driving columnarization of submucosal gland acini. Upon reaching the surface, the glandular acini opened up and gave rise to a glandular epithelium reminiscent of $\mathrm{BE}$ and showed expression of the columnar marker KRT7. ${ }^{56}$ However, no mucin production was observed in vitro, possibly due to the limited culture conditions.

Finally, a cross-sectional study by Bartel et al., where 515 normal squamous epithelial biopsies were examined from 106 treatment-naive BE patients, found a high percentage (39\% and 21\%) of subsquamous intestinal metaplastic glands at 5 and $10 \mathrm{~mm}$ from the $\mathrm{SCJ}$, respectively. ${ }^{57}$ Although not conclusive, these data also suggest BE could arise from the submucosal region.

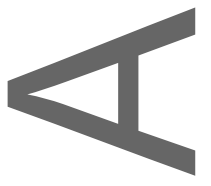

This article is protected by copyright. All rights reserved. 
There is still a lack of consensus on the cell of origin of BE. This is important as identification of the source would allow for more targeted and effective treatments and prevent recurrence of $\mathrm{BE}$ and/or EAC. Most of the current hypotheses on the origin of BE are based on mice and rat models, which have a different anatomy compared with humans. Furthermore, development of BE in the former only happens through some effort, either through genetic or surgical interventions. Surgical models are arguably the closest to a normal situation to rapidly promote the development of BE. However, the technicaldifficulties, postoperative state, and nonphysiologic levels of acid and bile exposures created in these models represent additional points of contention.

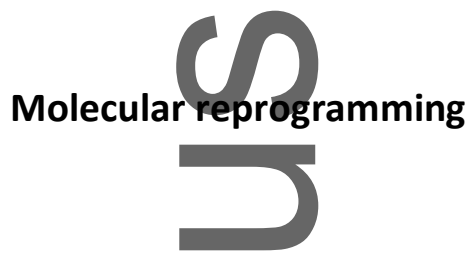

Although the exact identity of the BE cell of origin remains unknown, some type of molecular reprograming is required for the formation of an intestinal epithelium. These signaling pathways in Barrett's epithelium can be divided into those that participate in intestinalization, contribute to a proliferative advantage, or mediate inflammation. Given how Barrett's epithelium histologically resembles intestinal epithelium, it is not surprising that several developmental signaling pathways active in the normal adult intestine are also active in BE. These include $\mathrm{Wnt} / \beta$-catenin, Notch, Hedgehog, BMP, and TGF.$^{58}$ Notch and Wnt are closely intertwined in embryological development and are important in normal intestinal development. Hedgehog and BMP4 are expressed in the embryonic esophagus to maintain a columnar phenotype. ${ }^{1} \mathrm{Wnt} / \beta$-catenin signaling occurs normally in intestinal crypt stem cells. ${ }^{59}$ In the absence of Wnt ligand, $\beta$-catenin is degraded by a complex that contains the tumor suppressor adenomatous polyposis coli (APC). However, in the presence of Wnt ligand, $\beta$-catenin is stabilized and translocates to the nucleus where it complexes with TCF/LEF to transactivate pathway targets. In BE, promoter hypermethylation of APC occurs, leading to decreased APC expression and increased expression of Wnt target genes such as the stem cell marker DCLK1. ${ }^{60,61}$ How Wnt directly contributes to an intestinal phenotype in BE has not yet been clearly elucidated. Similar to Wnt, Notch pathway activity is high in intestinal crypt stem cells. ${ }^{62}$ Signaling begins when ligand binds to a Notch receptor. This leads to cleavage by the $\gamma$ secretase complex, generating the Notch intracellular domain (NICD), which can translocate to the nucleus and transactivate pathway targets such as Hes1. Progressively decreasing Notch activity along the cryptvillus axis in the intestine leads to differentiation towards the villus and a secretory cell phenotype 
such as is found in enteroendocrine, Paneth, and goblet cells. ${ }^{63}$ In rats, Notch signaling is not present in normal esophageal squamous epithelium. However, following esophagojejunostomy to surgically induce bile reflux into the esophagus, Notch signaling is activated as demonstrated by expression of NICD and columnar metaplasia occurs. When these rats were subsequently treated with a $\gamma$ secretase inhibitor to inhibit Notch signaling, mucus hyperplasia occurred in the metaplastic columnar epithelium. ${ }^{64}$ These findings suggest that Notch could have a dual effect with early activation leading to a columnar phenotype and later downregulation inducing a secretory goblet cell. In human squamous esophageal HET-1A cells, treatment with deoxycholic acids led to downregulation of Hes1 and upregulation of $\mathrm{ATOH} 1$, which is normally suppressed by Hes1, in a dose-dependent fashion. ${ }^{65}$ ATOH1 then induces expression of the intestinal transcription factor CDX2, which itselfinduces expression of MUC2. In mammals, two Hedgehog ligands are expressed in the gastrointestinal tract. Indian hedgehog is secreted by differentiated epithelial cells of the colon and antagonizes Wht signaling found in crypt progenitor cells. ${ }^{66}$ Another Hedgehog ligand, Sonic hedgehog, is expressed in the early embryonic esophageal epithelium, and its expression is downregulated as embryonic development progresses and the esophageal epithelium becomes squamous and stratified. ${ }^{67}$ Both Hedgehog ligands activate expression of bone morphogenetic proteins (BMP), typically BMP2 or BMP4, in stromal fibroblasts. ${ }^{68,69}$ Reactivation of Sonic hedgehog and ectopic activation of Indian hedgehog signaling occurs in human BE, leading to expression of BMP4 in adjacent esophageal fibroblasts. ${ }^{67}$ Stromal BMP4 can then act back on esophageal epithelium to activate expression of columnar genes and induce a columnar phenotype. ${ }^{67,70}$ Transgenic overexpression of BMP4 in foregut epithelium of the mouse using the $\mathrm{Krt14}$ promoter led to columnar metaplasia followed by intestinalization when bile reflux through creation of an esophageal-jejunal fistula was induced. ${ }^{71}$ Finally, TGF $\beta$ is expressed in the differentiated compartment of the intestine, and its loss is one of the early events in colon cancer. ${ }^{72}$ TGF $\beta$ alterations are not often seen in non-dysplastic $B E$, but consistent with its role as a tumor suppressor, TGF $\beta$ expression is lost as BE progresses through dysplasia and into invasive cancer. ${ }^{73}$ These data show that activation of intestinal signaling pathways that both maintain intestinal stem cells and cause intestinal cell differentiation occurs in BE.

Acid- and bile acid-mediated activation of pro-proliferative signaling pathways, such as PI3K, p38MAPK, and ERK, and inflammatory pathways, such as NF-KB, in esophageal epithelial cells also 
contribute to metaplasia. Treatment of SKGT-4 cells, derived from a well-differentiated EAC arising from Barrett's esophaugus, with the bile acids glycochenodeoxycholate and taurocholic acid induced the gastric mucin gene MUC5AC. When bile acids and the PI3K inhibitor LY294002 were used simultaneously on SKGT-4 cells, MUC5AC expression was not induced, suggesting that PI3K mediates bile acid regulation of this mucin gene. ${ }^{74}$ Signaling through PI3K also mediates IL-4-induced downregulation of squamous genes KRT13 and involucrin and upregulation of the columnar genes KRT7 and KRT8 in normal human esophageal epithelial cells (HEECs). ${ }^{75}$ Treatment of the nondysplastic BE-celfline, BAR-T, with a conjugated bile acid led to increased proliferation as measured by cell number and BrdU incorporation. ${ }^{76}$ Higher levels of MEK1 phosphorylation at an inhibitory site and decreased MEK1/2 activity in response to acid exposure were seen in squamous epithelium from a patient with $\mathrm{BE}$ as compared with a patient with GERD without BE. ${ }^{77}$ Similarly, acid and bile salts increased expression of the transcription factor CDX2 in esophageal squamous epithelial cells from patients with $B E$ but not from patients with GERD without BE. ${ }^{78}$ This increase in CDX2 was dependent on NF-KB as demonstrated by treatment with the NF-KB pathway inhibitor BAY 11-7085 preventing CDX2 promoter activation. Thus, molecular differences in pro-proliferative and inflammatory signaling pathway activation in response to acid and bile exposure may favor differentiation towards a BE phenotype over a squamous phenotype.

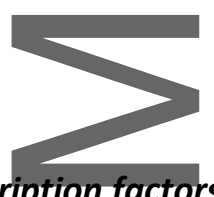

\section{Transcription factors Involved in Barrett's esophagus}

Transcription factors work downstream of signaling pathways to induce Barrett's metaplasia. Conceptually, this could start with downregulation of transcription factors that specify squamous differentiation and upregulation of transcription factors that specify columnar differentiation. ${ }^{79}$ This could be followed by intestinal differentiation with some cells differentiating into a secretory cell such as a goblet cell. SOX2 and p63 have dual roles as stem cell markers and squamous transcription factors. Mice heterozygous for a Sox 2 knockout allele and a Sox2 hypomorph allele develop esophagi lined by simple columnar epithelium with areas of multilayered epithelium and some cells containing mucus. ${ }^{80}$ Knockout of $p 63$ in mice leads to embryonic lethality. Prior to birth, epithelial cells of the gastrointestinal tract proximal to the mouse SCJ were simple columnar and expressed mucin in the knockout embryos compared with stratified squamous epithelium without mucin in wild-type embryos. ${ }^{41}$ Human Barrett's epithelium does not express either SOX2 or p63, consistent with their 
roles as squamous transcription factors in the esophagus. ${ }^{51}$ Additional supporting data include the identification of SOX 2 as an oncogene in foregut squamous cell carcinomas and the finding that nitric oxide, found in high concentrations in patients with GERD, decreases SOX2 levels in esophageal epithelial cells while inducing CDX2 expression. ${ }^{81,82}$ SOX9, a target of Wnt signaling in intestinal crypts, is not normally expressed by esophageal epithelium, but it can be induced by surgically induced reflux in mice. ${ }^{83}$ In contrast with normal esophageal squamous epithelium, SOX9 is uniformly expressed in human BE and is a target gene of forced BMP4 signaling. ${ }^{67}$ SOX9 overexpression in human and mouse esophageal epithelium induced expression of the columnar genes KRT8 and KRT18 and a more columnar-like phenotype. ${ }^{67,84}$ CDX1 and CDX2 are homeobox genes that specify intestinal differentiation and are expressed by Barrett's epithelium. CDX1 overexpression in esophageal epithelial cells leads to upregulation of CDX2 ${ }^{85} \mathrm{Cdx} 2$ heterozygote mice develop intestinal adenomatous polyps covered with keratinized squamous epithelium, demonstrating the requirement for CDX2 to form normal intestine. ${ }^{86}$ Gene targets of CDX2 include the intestinal genes MUC2, Sucrose-Isomaltase, Villin, CK2O, and CDX2 itself. $^{79}$ Other intestinal transcription factors expressed in BE include GATA4 and GATA6. ${ }^{87}$ GATA4 and GATA6 are required for intestinal cytódifferentiation as compound knockout mice had a decreased number of enterocytes and enteroendocrine cells and an increased number of goblet cells. ${ }^{88}$ In the small intestine, GATA4 specifies jejunal versus ileal phenotype, while in embryonic cells, GATA6 positively regulates Indian hedgehog expression. ${ }^{87,} 89$ FOXA2 is a transcription factor expressed by Barrett's epithelium and its overexpression in squamous esophageal epithelial cells induced expression of MUC2. FOXA2 also upregulates expression of the gene AGR2, which is expressed in Barrett's epithelium and is required for post-translational modification of MUC2 to its mature form. ${ }^{90}$ KLF4 and KLF5 are zinc finger transcription factors which can be upregulated by bile acids and are expressed by Barrett's epithelium. ${ }^{85,91}$ KLF5 has been reported to be upregulated by bile acids and to positively regulate the expression of CDX2 leading to a columnar phenotype when KLF5 was overexpressed in esophageal squamous epithelial cells. ${ }^{91}$ KLF4 can be upregulated by BMP4 or bile acids via NF-KB signaling and is inhibited by Notch signaling, leading to squamous esophageal epithelium expressing columnar and mucin genes and downregulating squamous genes. ${ }^{85,92}$

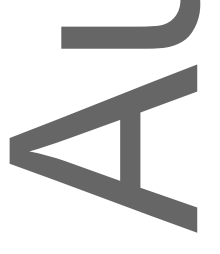

This article is protected by copyright. All rights reserved. 
More recently, the role of microRNAs (miRNAs) in Barrett's pathogenesis has been investigated. miRNAs are small, noncoding RNA molecules that silence their target gene expression. Comparison of squamous, BE, and EAC patient biopsies led to the identification of miR-215, miR-192, miR-194, miR-143, and miR-145 as being more highly expressed in Barrett's epithelium compared with squamous epithelium. ${ }^{93}$ Overexpression of miR-145 in squamous esophageal epithelial HET-1A cells and metaplastic BAR-T Barrett's cells led to decreased cellular proliferation and decreased mRNA levels of GATA6, BMP4, and SOX9. Treating cells with BMP4 led to decreased miR-145 levels. Based on these studies, the authors suggested that miR-145 maintains columnar metaplasia by adjusting levels of GATA6, BMP4, and SOX9 and preventing progression to cancer. miR-194, miR-200c, miR-21, and miR-122-5p are upregulated in BE and target various signaling pathways. miR-194 targets SUFU, a negative regulator of the Hedgehog pathway; loss of SUFU should increase Hedgehog pathway activity and target gene expression. ${ }^{94}$ miR-200c targets the BMP inhibitor Noggin, leading to increased BMP sigraling, and the Notch ligand JAG1, leading to decreased Notch signaling. ${ }^{95}$ miR-21 and miR-122-5R target different Notch ligands and agonists, all of which would lead to loss of Notch signaling. . $^{95}$ R-21, miR-130b, and miR-181b are also upregulated in Barrett's epithelium and positively regulate $N F-K B$ signaling. Other miRNAs with altered expression in BE regulate the ERK, TGF $\beta$, and Wht pathways. ${ }^{95}$ Given miRNA regulation of many pathways involved in BE pathogenesis, further investigation of miRNA expression in patient tissues and validation of their proposed functions are warranted.

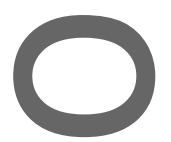

\section{Epigenetic mechanisms in Barrett's esophagus}

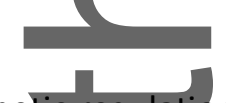

Epigenetic regulation of the above signaling pathways and transcription factors may also participate in the metaplastic process. It is known that as embryonic cells differentiate, their chromatin changes from a more open configuration to a more closed configuration. A second epigenetic mechanism is $\mathrm{CpG}$ island methylation in promoters leading to gene silencing. Treatment of esophageal squamous epithelial cells with the demethylating agent 5-aza-2'-deoxycytidine led to re-expression of CDX2, suggesting that reversal of epigenetic changes may play a role in BE pathogenesis. ${ }^{96}$ Furthermore, 
since FOXA and GATA proteins are pioneer transcription factors, they are able to initiate and maintain regions of open chromatin, which could lead to cell plasticity. ${ }^{97}$

Regardless of the exact molecular mechanism involved, reprogramming must occur in the BE cell of origin since none of the postulated cells would normally give rise to specialized intestinal metaplasia. The various cellular phenotypes seen in BE, such as stem cells to maintain Barrett's epithelium, proliferative intestinal glands, and columnar and differentiated intestinal cells, occurs through activation of signaling pathways, transcription factors, and miRNAs that are normally expressed in intestinal epithelium.

\section{क}

Conclusion

$\mathrm{BE}$ is an increasingly common condition and the only known precursor to EAC. Our understanding of the basic biology of Barrett's has progressed considerably in recent years. The development of BE is a complex interplay of environmental and anatomical factors, the breakdown of esophageal barrier function, and molecular and cellular pathways. Advancements in our knowledge and understanding of $\mathrm{BE}$ will hopefully improve our risk stratification ability and underpin the development of more targeted and effective therapeutic strategies to combat Barrett's carcinogenesis.

\section{Acknowledgements}

M.R. is the recipient of a senior lecturer fellowship from the Royal Australasian College of Surgeons.

\section{Authors contributions}

H.B., M.R., and L.C. organized and contributed to the final drafting of the review. Q.H. wrote the "Definition-of Barrett's esophagus and the significance of goblet cell metaplasia" section. S.R.G. wrote the "GERD and the role of the epithelium in maintaining barrier function" section. E.L. wrote the "Cell of origin controversy" section and assisted in editing. D.H.W. wrote the "Molecular reprogramming" section.

\section{Competing interests}

The authors declare no competing interests.

This article is protected by copyright. All rights reserved. 


\section{References}

1. Wang DH, Souza RF. Biology of Barrett's esophagus and esophageal adenocarcinoma. Gastrointestinal endoscopy clinics of North America. 2011;21(1):25-38.

2. Al-Batran SE, Hofheinz RD, Pauligk C, Kopp HG, Haag GM, Luley KB, et al. Histopathological regression after neoadjuvant docetaxel, oxaliplatin, fluorouracil, and leucovorin versus epirubicin, cisplatin, and fluorouracil or capecitabine in patients with resectable gastric or gastro-oesophageal junction adenocarcinoma (FLOT4-AIO): results from the phase 2 part of a multicentre, open-label, randomised phase 2/3 trial. The Lancet Oncology. 2016;17(12):1697-708.

3. Al-Batran SE, Homann N, Pauligk C, Goetze TO, Meiler J, Kasper S, et al. Perioperative chemotherapy with fluorouracil plus leucovorin, oxaliplatin, and docetaxel versus fluorouracil or capecitabine plus cisplatin and epirubicin for locally advanced, resectable gastric or gastrooesophageal junction adenocarcinoma (FLOT4): a randomised, phase 2/3 trial. Lancet (London, England). 2019;393(10184):1948-57.

4. Shapiro J, van Lanschot JJB, Hulshof M, van Hagen P, van Berge Henegouwen MI, Wijnhoven $\mathrm{BPL}$, et al. Neoadjuvant chemoradiotherapy plus surgery versus surgery alone for oesophageal or junctional cancer (CROSS): long-term results of a randomised controlled trial. The Lancet Oncology. 2015;16(9):1090-8.

5. Arnold M, Laversanne M, Brown LM, Devesa SS, Bray F. Predicting the Future Burden of Esophageal Cancer by Histological Subtype: International Trends in Incidence up to 2030. The American journal of gastroenterology. 2017;112(8):1247-55.

6. PohH H, Pech O, Arash H, Stolte M, Manner H, May A, et al. Length of Barrett's oesophagus and cancer risk: implications from a large sample of patients with early oesophageal adenocarcinoma. Gut. 2016;65(2):196-201.

7. Parasa S, Vennalaganti S, Gaddam S, Vennalaganti P, Young P, Gupta N, et al. Development and Validation of a Model to Determine Risk of Progression of Barrett's Esophagus to Neoplasia. Gastroenterology 2018;154(5):1282-9.e2.

8. Krishnamoorthi R, Lewis JT, Krishna M, Crews NJ, Johnson ML, Dierkhising RA, et al. Predictors of Progression in Barrett's Esophagus with Low-Grade Dysplasia: Results from a Multicenter Prospective BE Registry. American Journal of Gastroenterology. 2017;112(6):867-73.

9. Sawas T, Killcoyne S, Iyer PG, Wang KK, Smyrk TC, Kisiel JB, et al. Identification of Prognostic Phenotypes of Esophageal Adenocarcinoma in 2 Independent Cohorts. Gastroenterology. 2018;155(6):1720-8.e4.

10. Clermont M, Falk GW. Clinical Guidelines Update on the Diagnosis and Management of Barrett's Esophagus. Digestive Diseases and Sciences. 2018;63(8):2122-8.

This article is protected by copyright. All rights reserved. 
11. Fitzgerald RC, di Pietro M, Ragunath K, Ang Y, Kang JY, Watson P, et al. British Society of Gastroenterology guidelines on the diagnosis and management of Barrett's oesophagus. Gut. 2014;63(1):7-42.

12. Fock KM, Talley N, Goh KL, Sugano K, Katelaris P, Holtmann G, et al. Asia-Pacific consensus on the management of gastro-oesophageal reflux disease: an update focusing on refractory reflux disease and Barrett's oesophagus. Gut. 2016;65(9):1402-15.

13. Whiteman DC, Appleyard M, Bahin FF, Bobryshev YV, Bourke MJ, Brown I, et al. Australian clinical practice guidelines for the diagnosis and management of Barrett's esophagus and early esophageal adenocarcinoma. Journal of gastroenterology and hepatology. 2015;30(5):804-20.

14. Qumseya B, Sultan S, Bain P, Jamil L, Jacobson B, Anandasabapathy S, et al. ASGE guideline on screening and surveillance of Barrett's esophagus. Gastrointestinal endoscopy. 2019;90(3):33559.e2.

15. Weusten B, Bisschops R, Coron E, Dinis-Ribeiro M, Dumonceau JM, Esteban JM, et al. Endoscopic management of Barrett's esophagus: European Society of Gastrointestinal Endoscopy (ESGE) Position Statement. Endoscopy. 2017;49(2):191-8.

16. Shaheen NJ, Falk GW, lyer PG, Gerson LB. ACG Clinical Guideline: Diagnosis and Management of Barrett's Esophagus. The American journal of gastroenterology. 2016;111(1):30-50; quiz 1.

17. Younes $M$, Ertan A, Ergun G, Verm R, Bridges M, Woods K, et al. Goblet Cell Mimickers in Esophageal Biopsies Are Not Associated With an Increased Risk for Dysplasia. Archives of Pathology \& Laboratory Medicine. 2007;131(4):571-5.

18. Westerhoff M, Hovan L, Lee C, Hart J. Effects of dropping the requirement for goblet cells from the diagnosis of Barrett's esophagus. Clinical gastroenterology and hepatology : the official clinical practice journal of the American Gastroenterological Association. 2012;10(11):1232-6.

19. Bandla S, Peters JH, Ruff D, Chen SM, Li CY, Song K, et al. Comparison of cancer-associated genetic abnormalities in columnar-lined esophagus tissues with and without goblet cells. Ann Surg. 2014;260(1);72-80.

20. Boeckxstaens GE. Review article: the pathophysiology of gastro-oesophageal reflux disease. Alimentary pharmacology \& therapeutics. 2007;26(2):149-60.

21. Vandenplas $Y$, Hassall E. Mechanisms of gastroesophageal reflux and gastroesophageal reflux disease. J Pediatr Gastroenterol Nutr. 2002;35(2):119-36.

22. Younes $\mathrm{ZH}$. Role of growth factors in oesophageal mucosal healing: A work in progress. Journal of gastroenterology and hepatology. 1998;13(11):S156.

This article is protected by copyright. All rights reserved. 
23. Blevins $\mathrm{CH}$, Iyer PG, Vela MF, Katzka DA. The Esophageal Epithelial Barrier in Health and Disease. Clinical gastroenterology and hepatology : the official clinical practice journal of the American Gastroenterological Association. 2018;16(5):608-17.

24. Orlando RC, Lacy ER, Tobey NA, Cowart K. Barriers to paracellular permeability in rabbit esophageal epithelium. Gastroenterology. 1992;102(3):910-23.

25. Sandilands A, Sutherland C, Irvine AD, McLean WH. Filaggrin in the frontline: role in skin barrier function and disease. Journal of cell science. 2009;122(Pt 9):1285-94.

26. Orlando RC. The integrity of the esophageal mucosa. Balance between offensive and defensive mechanisms. Best Pract Res Clin Gastroenterol. 2010;24(6):873-82.

27. Sinnatamby CS. Last's Anatomy Regional and Applied. 12th ed: Elsevier; 2011.

28. Boeckxstaens GE, Rohof WO. Pathophysiology of gastroesophageal reflux disease. Gastroenterology clinics of North America. 2014;43(1):15-25.

29. Souza RF, Huo X, Mittal V, Schuler CM, Carmack SW, Zhang HY, et al. Gastroesophageal reflux might cause esophagitis through a cytokine-mediated mechanism rather than caustic acid injury. Gastroenterology. 2009;137(5):1776-84.

30. Quante M, Bhagat G, Abrams JA, Marache F, Good P, Lee MD, et al. Bile acid and inflammation activate gastric cardia stem cells in a mouse model of Barrett-like metaplasia. Cancer Cell. 2012;21(1):36-51.

31. Calle EE, Kaaks R. Overweight, obesity and cancer: epidemiological evidence and proposed mechanisms. Nat Rev Cancer. 2004;4(8):579-91.

32. Darido C, Georgy SR, Wilanowski T, Dworkin S, Auden A, Zhao Q, et al. Targeting of the tumor suppressor GRHL3 by a miR-21-dependent proto-oncogenic network results in PTEN loss and tumorigenesis. Cancer Cell. 2011;20(5):635-48.

33. Georgy SR, Cangkrama M, Srivastava S, Partridge D, Auden A, Dworkin S, et al. Identification of a Novel Proto-oncogenic Network in Head and Neck Squamous Cell Carcinoma. Journal of the National Cancer Institute. 2015;107(9).

34. Fagerberg $\downarrow$, Hallstrom BM, Oksvold P, Kampf C, Djureinovic D, Odeberg J, et al. Analysis of the human tissue-specific expression by genome-wide integration of transcriptomics and antibodybased proteomics. Molecular \& cellular proteomics : MCP. 2014;13(2):397-406.

35. Kim SM, Park YY, Park ES, Cho JY, Izzo JG, Zhang D, et al. Prognostic biomarkers for esophageal adenocarcinoma identified by analysis of tumor transcriptome. Plos one. 2010;5(11):e15074.

This article is protected by copyright. All rights reserved. 
36. Menke V, Van Zoest KP, Moons LM, Pot RG, Siersema PD, Kuipers EJ, et al. Myo9B is associated with an increased risk of Barrett's esophagus and esophageal adenocarcinoma. Scandinavian journal of gastroenterology. 2012;47(12):1422-8.

37. Marcinkiewicz M, Grabowska SZ, Czyzewska E. Role of epidermal growth factor (EGF) in oesophageal mucosal integrity. Curr Med Res Opin. 1998;14(3):145-53.

38. Bremner CG, Lynch VP, Ellis FH, Jr. Barrett's esophagus: congenital or acquired? An experimental study of esophageal mucosal regeneration in the dog. Surgery. 1970;68(1):209-16.

39. Quante M, Bhagat G, Abrams JA, Marache F, Good P, Lee MD, et al. Bile acid and inflammation activate gastric cardia stem cells in a mouse model of Barrett-like metaplasia. Cancer cell. 2012;21(1):36-51.

40. Fitzgerald RC, Abdalla S, Onwuegbusi BA, Sirieix P, Saeed IT, Burnham WR, et al. Inflammatory gradient in Barrett's oesophagus: implications for disease complications. Gut. 2002;51(3):316-22.

41. Wang $X$, Ouyang $H$, Yamamoto $Y$, Kumar PA, Wei TS, Dagher R, et al. Residual embryonic cells as precursors of a Barrett's-like metaplasia. Cell. 2011;145(7):1023-35.

42. Daniely $\mathrm{Y}$, Liao G, Dixon D, Linnoila RI, Lori A, Randell SH, et al. Critical role of p63 in the development of a normal esophageal and tracheobronchial epithelium. American journal of physiology Cell physiology. 2004;287(1):C171-81.

43. Jiang $M$, Li $H$, Zhang $Y$, Yang $Y$, Lu R, Liu K, et al. Transitional basal cells at the squamouscolumnar junction generate Barrett's oesophagus. Nature. 2017;550(7677):529-33.

44. Sarosi G, Brown G, Jaiswal K, Feagins LA, Lee E, Crook TW, et al. Bone marrow progenitor cells contribute to esophageal regeneration and metaplasia in a rat model of Barrett's esophagus. Diseases of the esophagus : official journal of the International Society for Diseases of the Esophagus. 2008;21(1):43-50.

45. Wang DH. The Esophageal Squamous Epithelial Cell-Still a Reasonable Candidate for the Barrett's Esophagus Cell of Origin? Cellular and molecular gastroenterology and hepatology. 2017;4(1):157-60.

46. Shields HM, Zwas F, Antonioli DA, Doos WG, Kim S, Spechler SJ. Detection by scanning electron microscopy of a distinctive esophageal surface cell at the junction of squamous and Barrett's epithelium. Dig Dis Sci. 1993;38(1):97-108.

47. Evans JA, McDonald SA. The Complex, Clonal, and Controversial Nature of Barrett's Esophagus. Adv Exp Med Biol. 2016;908:27-40.

This article is protected by copyright. All rights reserved. 
48. Nicholson AM, Graham TA, Simpson A, Humphries A, Burch N, Rodriguez-Justo $M$, et al. Barrett's metaplasia glands are clonal, contain multiple stem cells and share a common squamous progenitor. Gut. 2012;61(10):1380-9.

49. Shields HM, Rosenberg SJ, Zwas FR, Ransil BJ, Lembo AJ, Odze R. Prospective evaluation of multilayered epithelium in Barrett's esophagus. The American journal of gastroenterology. 2001;96(12):3268-73.

50. Boch JA, Shields HM, Antonioli DA, Zwas F, Sawhney RA, Trier JS. Distribution of cytokeratin markers in Barrett's specialized columnar epithelium. Gastroenterology. 1997;112(3):760-5.

51. Chen X, Qin R, Liu B, Ma Y, Su Y, Yang CS, et al. Multilayered epithelium in a rat model and human Barrett's esophagus: similar expression patterns of transcription factors and differentiation markers. BMC Gastroenterol. 2008;8:1.

52. Gillen $P$, Keeling P, Byrne PJ, West AB, Hennessy TP. Experimental columnar metaplasia in the canine oesophagus. The British journal of surgery. 1988;75(2):113-5.

53. Coad RA, Woodman AC, Warner PJ, Barr H, Wright NA, Shepherd NA. On the histogenesis of Barrett's oesophagus and its associated squamous islands: a three-dimensional study of their morphological relationship with native oesophageal gland ducts. J Pathol. 2005;206(4):388-94.

54. Lörinc $\mathrm{E}$, Öberg S. Submucosal glands in the columnar-lined oesophagus: evidence of an association with metaplasia and neosquamous epithelium. Histopathology. 2012;61(1):53-8.

55. Leedham SJ, Preston SL, McDonald SA, Elia G, Bhandari P, Poller D, et al. Individual crypt genetic heterogeneity and the origin of metaplastic glandular epithelium in human Barrett's oesophagus. Gut. 2008;57(8):1041-8.

56. Chang C-L, Lao-Sirieix P, Save V, De La Cueva Mendez G, Laskey R, Fitzgerald RC. Retinoic acid-induced glandular differentiation of the oesophagus. Gut. 2007;56(7):906-17.

57. Bartel MJ, Srivastava A, Gordon S, Rothstein RI, Pohl H. Subsquamous intestinal metaplasia is common in treatment-naive Barrett's esophagus. Gastrointest Endosc. 2018;87(1):67-74.

58. Sancho E, Batlle E, Clevers H. Signaling pathways in intestinal development and cancer. Annu Rev CellDev Biol. 2004;20:695-723.

59. Pinto D, Gregorieff A, Begthel H, Clevers H. Canonical Wnt signals are essential for homeostasis of the intestinal epithelium. Genes Dev. 2003;17(14):1709-13.

60. Clement G, Braunschweig R, Pasquier N, Bosman FT, Benhattar J. Alterations of the Wnt signaling pathway during the neoplastic progression of Barrett's esophagus. Oncogene. 2006;25(21):3084-92.

This article is protected by copyright. All rights reserved. 
61. Vega KJ, May R, Sureban SM, Lightfoot SA, Qu D, Reed A, et al. Identification of the putative intestinal stem cell marker doublecortin and CaM kinase-like-1 in Barrett's esophagus and esophageal adenocarcinoma. Journal of gastroenterology and hepatology. 2012;27(4):773-80.

62. Fre $S$, Huyghe $M$, Mourikis $P$, Robine $S$, Louvard D, Artavanis-Tsakonas S. Notch signals control the fate of immature progenitor cells in the intestine. Nature. 2005;435(7044):964-8.

63. VanDussen KL, Carulli AJ, Keeley TM, Patel SR, Puthoff BJ, Magness ST, et al. Notch signaling modulates proliferation and differentiation of intestinal crypt base columnar stem cells. Development. 2012;139(3):488-97.

64. Menke V, van Es JH, de Lau W, van den Born M, Kuipers EJ, Siersema PD, et al. Conversion of metaplastic Barrett's epithelium into post-mitotic goblet cells by gamma-secretase inhibition. Dis Model Mech. 2010;3(1-2):104-10.

65. Tamagawa $\mathrm{Y}$, Ishimura N, Uno G, Yuki T, Kazumori H, Ishihara S, et al. Notch signaling pathway and Cdx2 expression in the development of Barrett's esophagus. Lab Invest. 2012.

66. van den Brink GR, Bleuming SA, Hardwick JC, Schepman BL, Offerhaus GJ, Keller JJ, et al. Indian Hedgehog is an antagonist of Wnt signaling in colonic epithelial cell differentiation. Nature genetics. 2004;36(3):277-82.

67. Wang DH, Clemons NJ, Miyashita T, Dupuy AJ, Zhang W, Szczepny A, et al. Aberrant epithelial-mesenchymal Hedgehog signaling characterizes Barrett's metaplasia. Gastroenterology. 2010;138(5):1810-22.

68. Roberts DJ, Johnson RL, Burke AC, Nelson CE, Morgan BA, Tabin C. Sonic hedgehog is an endodermal signal inducing Bmp-4 and Hox genes during induction and regionalization of the chick hindgut. Development. 1995;121(10):3163-74.

69. Roberts DJ, Smith DM, Goff DJ, Tabin CJ. Epithelial-mesenchymal signaling during the regionalization of the chick gut. Development. 1998;125(15):2791-801.

70. Milano F, van Baal JW, Buttar NS, Rygiel AM, de Kort F, DeMars CJ, et al. Bone morphogenetic protein 4 expressed in esophagitis induces a columnar phenotype in esophageal squamous cells. Gastroenterology. 2007;132(7):2412-21.

71. Mari L, Milano F, Parikh K, Straub D, Everts V, Hoeben KK, et al. A pSMAD/CDX2 complex is essential for the intestinalization of epithelial metaplasia. Cell reports. 2014;7(4):1197-210.

72. Winesett MP, Ramsey GW, Barnard JA. Type II TGF(beta) receptor expression in intestinal cell lines and in the intestinal tract. Carcinogenesis. 1996;17(5):989-95.

73. Zeng J, Kelbauskas L, Rezaie A, Lee K, Ueberroth B, Gao W, et al. Transcriptional regulation by normal epithelium of premalignant to malignant progression in Barrett's esophagus. Scientific reports. 2016;6:35227.

This article is protected by copyright. All rights reserved. 
74. Song S, Byrd JC, Guha S, Liu KF, Koul D, Bresalier RS. Induction of MUC5AC mucin by conjugated bile acids in the esophagus involves the phosphatidylinositol 3-kinase/protein kinase C/activator protein-1 pathway. Cancer. 2011;117(11):2386-97.

75. Shan J, Oshima T, Farre R, Fukui H, Watari J, Miwa H. IL-4 induces columnar-like differentiation of esophageal squamous epithelium through JAK/PI3K pathway: possible role in pathogenesis of Barrett's esophagus. American journal of physiology Gastrointestinal and liver physiology $2014 ; 306(8): G 641-9$.

76. Jaiswal K, Lopez-Guzman C, Souza RF, Spechler SJ, Sarosi GA, Jr. Bile salt exposure increases proliferation through p38 and ERK MAPK pathways in a non-neoplastic Barrett's cell line. American journal of physiology Gastrointestinal and liver physiology. 2006;290(2):G335-42.

77. Zhang HY, Zhang X, Chen X, Thomas D, Hormi-Carver K, Elder F, et al. Differences in activity and phosphorylation of MAPK enzymes in esophageal squamous cells of GERD patients with and without Barrett's esophagus. American journal of physiology Gastrointestinal and liver physiology. 2008;295(3):G470-8.

78. Huo X, Zhang HY, Zhang XI, Lynch JP, Strauch ED, Wang JY, et al. Acid and bile salt-induced CDX2 expression differs in esophageal squamous cells from patients with and without Barrett's esophagus. Gastroenterology. 2010;139(1):194-203 e1.

79. Wang DH, Souza RF. Transcommitment: Paving the Way to Barrett's Metaplasia. Adv Exp Med Biol. 2016;908:183-212.

80. Que J, Okubo T, Goldenring JR, Nam KT, Kurotani R, Morrisey EE, et al. Multiple dosedependent roles for Sox 2 in the patterning and differentiation of anterior foregut endoderm. Development. 2007;134(13):2521-31.

81. Bass AJ, Watanabe H, Mermel CH, Yu S, Perner S, Verhaak RG, et al. SOX2 is an amplified lineage-survival oncogene in lung and esophageal squamous cell carcinomas. Nature genetics. 2009;41(11);1238-42.

82. Asanuma K, Huo X, Agoston A, Zhang X, Yu C, Cheng E, et al. In oesophageal squamous cells, nitric oxide causes S-nitrosylation of Akt and blocks SOX2 (sex determining region Y-box 2) expression. Gut. 2015.

83. Pham TH, Genta RM, Spechler SJ, Souza RF, Wang DH. Development and characterization of a surgical mouse model of reflux esophagitis and Barrett's esophagus. Journal of gastrointestinal surgery : official journal of the Society for Surgery of the Alimentary Tract. 2014;18(2):234-40; discussion 40-1.

84. Clemons NJ, Wang DH, Croagh D, Tikoo A, Fennell CM, Murone C, et al. Sox9 drives columnar differentiation of esophageal squamous epithelium: a possible role in the pathogenesis of Barrett's esophagus. American journal of physiology Gastrointestinal and liver physiology. 2012;303(12):G1335-46.

This article is protected by copyright. All rights reserved. 
85. Kazumori $\mathrm{H}$, Ishihara $\mathrm{S}$, Kinoshita $\mathrm{Y}$. Roles of caudal-related homeobox gene $\mathrm{Cdx} 1$ in oesophageal epithelial cells in Barrett's epithelium development. Gut. 2009;58(5):620-8.

86. Chawengsaksophak K, James R, Hammond VE, Kontgen F, Beck F. Homeosis and intestinal tumours in Cdx2 mutant mice. Nature. 1997;386(6620):84-7.

87. Haveri $H$, Westerholm-Ormio $M$, Lindfors $K$, Maki M, Savilahti E, Andersson LC, et al. Transcription factors GATA-4 and GATA- 6 in normal and neoplastic human gastrointestinal mucosa. BMC Gastroenterol. 2008;8:9.

88. Walker EM, Thompson CA, Battle MA. GATA4 and GATA6 regulate intestinal epithelial cytodifferentiation during development. Developmental biology. 2014;392(2):283-94.

89. Thompson CA, Wojta K, Pulakanti K, Rao S, Dawson P, Battle MA. GATA4 Is Sufficient to Establish Jejunal Versus lleal Identity in the Small Intestine. Cellular and molecular gastroenterology and hepatology. 2017;3(3):422-46.

90. Wang DH, Tiwari A, Kim ME, Clemons NJ, Regmi NL, Hodges WA, et al. Hedgehog signaling regulates FOXA2 in esophageal embryogenesis and Barrett's metaplasia. The Journal of clinical investigation. 2014;124(9):3767-80.

91. Xia $Y$, Fang $Y$, Zhang $H$, Shen $C$, Wang $P$, Yan $W$, et al. Role of Kruppel-Like Factor 5 in Deoxycholic Acid-Mediated Intestinal Transdifferentiation of Esophageal Squamous Epithelium. Journal of Cancer.2019;10(22):5597-607.

92. Vega ME, Giroux V, Natsuizaka M, Liu M, Klein-Szanto AJ, Stairs DB, et al. Inhibition of Notch signaling enhances transdifferentiation of the esophageal squamous epithelium towards a Barrett'slike metaplasia via KLF4. Cell Cycle. 2014;13(24):3857-66.

93. van Baal JW, Verbeek RE, Bus $P$, Fassan $M$, Souza RF, Rugge $M$, et al. microRNA-145 in Barrett's oesophagus: regulating BMP4 signalling via GATA6. Gut. 2013;62(5):664-75.

94. Wijhhoven BP, Hussey DJ, Watson DI, Tsykin A, Smith CM, Michael MZ, et al. MicroRNA profiling of Barrett's oesophagus and oesophageal adenocarcinoma. The British journal of surgery. 2010;97(6):853-61.

95. Clark RJ, Graig MP, Agrawal S, Kadakia M. microRNA involvement in the onset and progression of Barrett's esophagus: a systematic review. Oncotarget. 2018;9(8):8179-96.

96. Liu T, Zhang X, So CK, Wang S, Wang P, Yan L, et al. Regulation of Cdx2 expression by promoter methylation, and effects of $\mathrm{Cdx} 2$ transfection on morphology and gene expression of human esophageałepithelial cells. Carcinogenesis. 2007;28(2):488-96.

97. Watts JA, Zhang C, Klein-Szanto AJ, Kormish JD, Fu J, Zhang MQ, et al. Study of FoxA pioneer factor at silent genes reveals Rfx-repressed enhancer at $\mathrm{Cdx} 2$ and a potential indicator of esophageal adenocarcinoma development. PLoS Genet. 2011;7(9):e1002277.

This article is protected by copyright. All rights reserved. 


\section{University Library}

\section{- M M N E R VA A gateway to Melbourne's research publications}

Minerva Access is the Institutional Repository of The University of Melbourne

Author/s:

Badgery, H;Chong, L;lich, E;Huang, Q;Georgy, SR;Wang, DH;Read, M

Title:

Recent insights into the biology of Barrett's esophagus

Date:

2020-07-17

Citation:

Badgery, H., Chong, L., lich, E., Huang, Q., Georgy, S. R., Wang, D. H. \& Read, M. (2020).

Recent insights into the biology of Barrett's esophagus. ANNALS OF THE NEW YORK

ACADEMY OF SCIENCES, 1481 (1), pp.198-209. https://doi.org/10.1111/nyas.14432.

Persistent Link:

http://hdl.handle.net/11343/276022 